\title{
Controlled synthesis of single-chirality carbon nanotubes
}

Juan Ramon Sanchez-Valencia ${ }^{1} \dagger$, Thomas Dienel ${ }^{1}$, Oliver Gröning ${ }^{1}$, Ivan Shorubalko ${ }^{2}$, Andreas Mueller ${ }^{3} \dagger$, Martin Jansen $^{3}$, Konstantin Amsharov ${ }^{3} \dagger$, Pascal Ruffieux ${ }^{1} \&$ Roman Fasel $^{1,4}$

1nanotech@surfaces Laboratory, Empa, Swiss Federal Laboratories for Materials Science and Technology, 8600 Dübendorf, Switzerland.

${ }^{2}$ Laboratory for reliability science and technology, Empa, Swiss Federal Laboratories for Materials Science and Technology, 8600 Dübendorf, Switzerland.

${ }^{3}$ Max Planck Institute for Solid State Research, Heisenbergstrasse 1, 70569 Stuttgart, Germany.

${ }^{4}$ Department of Chemistry and Biochemistry, University of Bern, Freiestrasse 3, 3012 Bern, Switzerland

$\dagger$ Present addresses: Nanotechnology on Surfaces Laboratory, Instituto de Ciencia de Materiales de Sevilla (CSIC-US), Avda. Américo Vespucio 49, E-41092 Sevilla, Spain (J.R.S.-V.); BASF SE, GVM/I-L 544, 67056 Ludwigshafen, Germany (A.M.); University Erlangen-Nuremberg, Institut für Organische Chemie II, Henkestrasse 42, 91054 Erlangen, Germany (K.A.).

Over the last two decades, single-walled carbon nanotubes (SWCNTs) have received much attention because their extraordinary properties are promising for numerous applications $\mathbf{s}^{1,2}$. Many of these properties depend sensitively on SWCNT structure, which is characterized by the chiral index $(n, m)$ that denotes the length and orientation of the circumferential vector in the hexagonal carbon lattice. Electronic properties are particularly strongly affected, with subtle structural changes switching tubes from metallic to semiconducting with various bandgaps. Monodisperse 'single-chirality' (that is, with a single $(n, m)$ value) SWCNTs are thus needed to fully exploit their technological potential ${ }^{1,2}$. Controlled synthesis through catalyst engineering $^{3-6}$, end-cap engineering ${ }^{7}$ or cloning strategies ${ }^{8,9}$ and also tube sorting based on chromatography $^{10,11}$, density-gradient centrifugation, electrophoresis and other techniques ${ }^{12}$ have delivered SWCNT samples with narrow distributions of tube diameter and enriched in a particular tube type. But an effective pathway to truly monodisperse SWCNTs remains elusive. The use of template molecules to unambiguously dictate the diameter and chirality of the resulting nanotube $\mathrm{e}^{8,13-16}$ holds great promise in this regard, but has hitherto had only limited practical success ${ }^{7,17,18}$. Here we show that this bottom-up strategy can produce targeted nanotubes: we convert molecular precursors into ultrashort singly capped $(6,6)$ 'armchair' nanotube seeds using surface-catalysed cyclodehydrogenation on a Pt(111) surface, and then elongate these during a subsequent growth phase to produce single-chirality and essentially defect-free SWCNTs with lengths up to a few hundred nanometres. We expect that our onsurface synthesis approach will provide a route to nanotube-based materials with highly 


\section{optimized properties for applications such as light detectors, photovoltaics, field-effect transistors, and sensors ${ }^{2}$.}

Recent work has produced non-planar carbon-based nanostructures such as fullerenes, carbon pyramids, and buckybowls from their corresponding quasi-planar polycyclic aromatic hydrocarbon precursors through surface-catalysed cyclodehydrogenation $(\mathrm{CDH})^{19-21}$. We have extended the methodology to the synthesis of ultrashort singly capped SWCNTs, that is, a SWCNT end cap with a short tube segment attached. Such molecules represent ideal seeds for subsequent epitaxial elongation into isomerically pure SWCNTs. Formally, this approach mimics the conventional synthesis of SWCNTs by the root-growth mechanism, in which nanotube growth starts by nucleation of an end-cap fragment on a metal nanoparticle ${ }^{22}$. The key point is to avoid uncontrolled, spontaneous nucleation of end caps by providing atomically precise ultrashort nanotube seeds which unambiguously dictate the chiral index of SWCNTs forming on epitaxial elongation.

Precursor P1 ( $\mathrm{C}_{96} \mathrm{H}_{54}$; Fig. 1) was designed and synthesized by multi-step organic synthesis to tackle this challenge (for details, see Methods). Upon intramolecular CDH it affords seed S1, an ultra-short singly capped $(6,6)$ SWCNT bearing a carbon nanotube segment. The selective growth of $(6,6)$ SWCNTs is illustrated in Fig. 1 and combines two steps: (1) formation of seed S1, and (2) subsequent epitaxial elongation. The first step is realized by depositing precursor $\mathbf{P 1}$ on a $\operatorname{Pt}(111)$ surface followed by annealing to $770 \mathrm{~K}$ under ultrahigh vacuum conditions to induce the surfacecatalysed CDH reaction (Fig. 2a, b). The second step, epitaxial elongation, is achieved by the incorporation of carbon atoms originating from the surface-catalysed decomposition of a carbon feedstock gas (Fig. 3a-c).

Figure 2c shows a scanning tunnelling microscopy (STM) image acquired after depositing P1 on $\mathrm{Pt}(111)$. No step decoration or island formation is observed. Interactions with surrounding molecules and step edges are thus largely suppressed and ensure subsequent unperturbed CDH of the precursor $^{19,20}$. For the majority of the as-deposited precursors, STM reveals a three-fold symmetric conformation. However, the intrinsic axial chirality of the benzo[ $c]$ phenanthrene fragments ([4]helicene) (see Extended Data Fig. 1) and the configurational flexibility of the peripheral biphenyl fragments produce a large variety of possible geometries (Fig. 2c, Extended Data Fig. 1). The presence of axial chirality in the [4] helicene moieties results in four possible stereoisomers and thus eight possible adsorption geometries (Extended Data Fig. 1). An example of a molecule with its three outer biphenyl groups located closest to the surface is shown in Fig. 2e, together with the corresponding STM simulation based on the extended lowest unoccupied molecular orbital (LUMO; see Methods). The excellent agreement between STM image and simulation (Extended Data Fig. 1) 
indicates that the different topographic features observed for the adsorbed precursors can be attributed to the different adsorption geometries. Importantly, the stereoisomerism does not affect the $\mathrm{CDH}$ process, since all chiral centres will disappear during intramolecular cyclization.

Although P1 is designed to yield seed S1, the conformational flexibility of the peripheral biphenyl groups leads partially to undesired adsorption geometries. In contrast to the stereoisomers discussed above, these molecules will follow a different $\mathrm{CDH}$ pathway, ending in the formation of undesired buckybowls (Extended Data Fig. 2). A statistical analysis of more than 100 precursor monomers observed by STM revealed that more than 50\% adopt the desired configurations (Extended Data Fig. 1). Most importantly, the condensation products of precursor molecules exhibiting 'wrong' conformations cannot act as seeds for the subsequent CNT growth process via epitaxial elongation, and thus will not affect the selectivity of SWCNT formation.

Surface-catalysed CDH of precursors (P1) into seeds (S1) is induced by annealing at $770 \mathrm{~K}$ for $10 \mathrm{~min}$. STM images (Fig. 2d) show that the originally quasi-planar three-fold symmetric molecules transform into dome-shaped species with a prominent increase in apparent height from 2 to $4.5 \AA$ (Fig. 2f). Additional proof of successful dehydrogenation of P1 into $\mathbf{S 1}$ derives from the good agreement of high-resolution STM images and simulations of the frontier molecular orbitals of S1 (Fig. 2g). Both results demonstrate the successful formation of the targeted singly capped ultrashort $(6,6)$ SWCNT S1.

In the second step, the surface-anchored seeds $\mathbf{S 1}$ are grown into $(6,6)$ SWCNTs via epitaxial elongation by exposing them to a carbon feedstock gas such as ethylene or ethanol at temperatures between 670 and $770 \mathrm{~K}$ (see schematic illustration in Fig. 3a-c). The pre-synthesized seeds S1 are extended by catalytic epitaxial elongation, which consists of a consecutive incorporation of carbon atoms (schematically shown as $\mathrm{C}_{2}$ ) originating from the decomposition of ethanol or ethylene. The open part of $\mathbf{S 1}$ is already in the required contact with the $\operatorname{Pt}(111)$ surface, which catalyses further epitaxial elongation. In order to unambiguously demonstrate the activity of $\mathbf{S 1}$ in an epitaxial elongation process, the results of low exposures to carbon feedstock gas were followed in situ by STM. Low doses of ethylene at $770 \mathrm{~K}$ produce a substantial increase in apparent height from 4 to $20 \AA$ (Fig. 3d-g). After exposure to 1 Langmuir (L) of ethylene, about $18 \%$ of the initially deposited precursors P1 have grown into SWCNTs, a density that remains constant for higher exposures of $5 \mathrm{~L}$. Exposure to yet higher doses of ethylene or ethanol produces strong changes in the surface topography and makes STM imaging increasingly difficult (Fig. 3h). The topography becomes rough and the Pt surface is no longer discernible. Careful examination of the STM images reveals the presence of one-dimensional structures lying across the surface (Fig. 3h), with an abundance of about 
5 per $\mu \mathrm{m}^{2}$ and observed lengths exceeding $200 \mathrm{~nm}$. High resolution images of the elongated structures (Fig. 3i) reveal an internal structure of higher contrast lines along the direction of the tube axis. A superimposed structural model clearly shows that these lines are indeed the carbon positions of the graphene structure in a $(6,6)$ SWCNT. In all cases where atomic resolution of the tubes could be achieved, the structure proved to be consistent with a $(6,6)$ SWCNT. The outstanding agreement of both the orientation and the periodicity of the graphene lattice with those expected demonstrate that the one-dimensional structures are the targeted $(6,6)$ SWCNTs, bent horizontally across the sample surface.

To further corroborate the density and length of the horizontally aligned SWCNTs, the previous sample was imaged with a scanning helium ion microscope (SHIM). Tubes longer than $300 \mathrm{~nm}$ and with diameters below $2 \mathrm{~nm}$ (the highest resolution achieved) could be observed (Extended Data Fig. 3), with a density of 3-4 tubes per $\mu \mathrm{m}^{2}$ that is similar to the density estimated from STM images $\left(5\right.$ per $\left.\mu \mathrm{m}^{2}\right)$. We note that both STM and SHIM can only image horizontally aligned SWCNTs, but do not give access to vertically aligned SWCNTs.

To shed light on the orientation of the SWCNTs and to characterize the selectivity of the growth process, Raman characterization was performed. Measurements with the illuminating laser beam at normal incidence (perpendicular to the surface plane) yielded extremely low intensities; the $\mathrm{G}$ band, the most intense feature at around $1,590 \mathrm{~cm}^{-1}$, is very weak (grey curve in Fig. 4a). However, when samples were measured under an illumination angle of $30^{\circ}$, all bands increased significantly in intensity (black curve in Fig. 4a), as expected for a dominant fraction of SWCNTs oriented perpendicular to the surface. The polarizability of these vertically oriented tubes with the illuminating laser beam at normal incidence - and thus the electromagnetic field vector perpendicular to the tube axis - is drastically reduced, resulting in weak Raman intensities ${ }^{23}$. A predominantly vertical alignment of the SWCNTs is consistent with the observation that in SHIM images some CNTs appear to shake under the ion beam (Extended Data Fig. 3), and with the rough surface seen in STM. It also implies that the overall SWCNT density is expected to be significantly higher than that estimated from the STM and SHIM data.

More importantly, the Raman spectra demonstrate the high selectivity of our growth process, which produces $(6,6)$ SWCNTs exclusively. The spectrum shown in Fig. 4b presents clearly defined bands at the positions expected for $(6,6)$ SWCNTs. The band at $295 \mathrm{~cm}^{-1}$ is associated with the radial breathing mode (RBM) whose frequency depends strongly on the nanotube diameter ${ }^{23}$. Empirical equations predict an RBM frequency of $280-295 \mathrm{~cm}^{-1}$ for $(6,6) \mathrm{SWCNTs}^{23}$. 
Experimentally, the RBM for $(6,6)$ SWCNTs deposited on $\mathrm{SiO}_{2}$ has been reported at around $289 \mathrm{~cm}^{-1}$ (ref. 24), but it is well known that the substrate plays a crucial role in the RBM position, explaining the small deviation observed ${ }^{25}$. Most importantly, our Raman spectra do not show any further bands within the RBM range (200-400 $\mathrm{cm}^{-1}$ ), which underlines the extremely high selectivity of the process. Another notable characteristic of the RBM is the exceptionally small width observed (the full-width at half-maximum, FWHM, is $3.5 \mathrm{~cm}^{-1}$, limited by the resolution of the instrument), which is as small as that from isolated individual small diameter SWCNTs (an FWHM of $\left.3 \mathrm{~cm}^{-1}\right)^{26}$. The Raman spectra reported here average over a large area (beam diameter 1.5-10 $\mu \mathrm{m}$ (inset in Fig. $4 \mathrm{~b})$ ), and thus reflect the properties of a large number of SWCNTs. The narrow RBM peak therefore demonstrates a very high degree of monodispersity.

The $\mathrm{G}$ band appears as a double peak at 1,518 and $1,591 \mathrm{~cm}^{-1}$. The significant curvature in small diameter SWCNTs causes a shift to lower frequencies of the optical vibrations associated with transverse (perpendicular to the tube axis) atomic displacements (the $\mathrm{G}^{-}$band) ${ }^{27}$. Although, to our knowledge, this splitting has not been observed experimentally for a $(6,6) \mathrm{SWCNT}$, the $\mathrm{G}^{+}$and $\mathrm{G}^{-}$ band splitting $\left(\Delta \omega_{\mathrm{G}}\right)$ has been predicted to be $83 \mathrm{~cm}^{-1}$ (ref. 28), in good agreement with the splitting that we observe $\left(\Delta \omega_{\mathrm{G}}=73 \mathrm{~cm}^{-1}\right)$. The additional peaks in the range from 400 to $1,200 \mathrm{~cm}^{-1}$ have previously been observed and used as evidence for the presence of armchair SWCNTs, since no peak in this range is present for semiconducting tubes ${ }^{29}$. Finally, the absence of any D band in the Raman spectra (Fig. 4b) further underlines the extreme cleanliness of our process that yields not only predefined single-chirality but also essentially defect-free SWCNTs.

These findings clearly illustrate that the use of a planar metal surface instead of metal nanoparticles effectively supresses spontaneous cap formation and that this, in combination with the use of a suitable precursor species to produce a desired cap, enables highly selective SWCNT fabrication. The entire in situ process and the low temperatures involved in both the CDH step $(770 \mathrm{~K})$ and the subsequent epitaxial elongation $(670 \mathrm{~K})$ are fully compatible with complementary metal oxide semiconductor (CMOS) technology, and our methods might therefore solve two pivotal challenges in the realization of CNT-based integrated circuits for digital electronics: to provide SWCNTs with identical electronic properties, and to integrate these SWCNTs in device architectures (which may be achieved by site-specific deposition of the molecular precursor and/or the catalyst film). However, further progress that aims to be technologically relevant requires a process with higher growth yields that ideally approach unity. While we see considerable scope for optimization of the present process (in terms of catalyst, temperatures, pressures, and so on), an alternative is to replace the substrate-catalysed epitaxial elongation step by a more efficient process, such as hot 
filament chemical vapour deposition ${ }^{30}$. This would also allow more flexibility in independently optimizing seed formation and tube elongation while simultaneously suppressing spontaneous SWCNT growth at both stages. Another logical extension of the process is to other SWCNTs where subtleties related to the chiral index of the seed may come into play.

Received 17 April; accepted 17 June 2014; doi:10.1038/nature13607.

1. Jorio, A., Dresselhaus, G. \& Dresselhaus, M. S. Carbon Nanotubes: Advanced Topics in the Synthesis, Structure, Properties, and Applications (Springer, 2008).

2. Jariwala, D., Sangwan, V. K., Lauhon, L. J., Marks, T. J. \& Hersam, M. C. Carbon nanomaterials for electronics, optoelectronics, photovoltaics, and sensing. Chem. Soc. Rev. 42, 2824-2860 (2013).

3. Wang, H. et al. Selective synthesis of $(9,8)$ single walled carbon nanotubes on cobalt incorporated TUD-1 catalysts. J. Am. Chem. Soc. 132, 16747-16749 (2010).

4. He, M. et al. Selective growth of SWNTs on partially reduced monometallic cobalt catalyst. Chem. Commun. 47, 1219-1221 (2011).

5. Chiang, W.-H. \& Mohan Sankaran, R. Linking catalyst composition to chirality distributions of as-grown single-walled carbon nanotubes by tuning $\mathrm{Ni}_{\mathrm{x}} \mathrm{Fe}_{1-\mathrm{x}}$ nanoparticles. Nature Mater. 8, 882-886 (2009).

6. Hong, G., Chen, Y., Li, P. \& Zhang, J. Controlling the growth of single-walled carbon nanotubes on surfaces using metal and non-metal catalysts. Carbon 50, 2067-2082 (2012).

7. $\mathrm{Yu}, \mathrm{X}$. et al. Cap formation engineering: from opened $\mathrm{C}_{60}$ to single-walled carbon nanotubes. Nano Lett. 10, 3343-3349 (2010).

8. Smalley, R. E. et al. Single wall carbon nanotube amplification: en route to a type-specific growth mechanism. J. Am. Chem. Soc. 128, 15824-15829 (2006).

9. Yao, Y., Feng, C., Zhang, J. \& Liu, Z. 'Cloning' of single-walled carbon nanotubes via open-end growth mechanism. Nano Lett. 9, 1673-1677 (2009).

10. Tu, X., Manohar, S., Jagota, A. \& Zheng, M. DNA sequence motifs for structure-specific recognition and separation of carbon nanotubes. Nature 460, 250-253 (2009).

11. Liu, H., Nishide, D., Tanaka, T. \& Kataura, H. Large-scale single-chirality separation of single-wall carbon nanotubes by simple gel chromatography. Nature Commun. 2, 309 (2011). 
12. Hersam, M. C. Progress towards monodisperse single-walled carbon nanotubes. Nature Nanotechnol. 3, 387-394 (2008).

13. Mueller, A., Amsharov, K. Y. \& Jansen, M. Synthesis of end-cap precursor molecules for (6, 6) armchair and $(9,0)$ zig-zag single-walled carbon nanotubes. Tetrahedr. Lett. 51, 32213225 (2010).

14. Bunz, U. H. F., Menning, S. \& Martín, N. para-Connected cyclophenylenes and hemispherical polyarenes: building blocks for single-walled carbon nanotubes? Angew. Chem. Int. Edn Engl. 51, 7094-7101 (2012).

15. Mueller, A. \& Amsharov, K. Y. Synthesis of precursors for large-diameter hemispherical buckybowls and precursors for short carbon nanotubes. Eur. J. Org. Chem. 2012, 6155-6164 (2012).

16. Omachi, H., Segawa, Y. \& Itami, K. Synthesis of cycloparaphenylenes and related carbon nanorings: a step toward the controlled synthesis of carbon nanotubes. Acc. Chem. Res. 45, 1378-1389 (2012).

17. Mueller, A., Amsharov, K. Y. \& Jansen, M. End-cap precursor molecules for the controlled growth of single-walled carbon nanotubes. Fullerenes Nanotubes Carbon Nanostruct. 20, 401-404 (2012).

18. Omachi, H., Nakayama, T., Takahashi, E., Segawa, Y. \& Itami, K. Initiation of carbon nanotube growth by well-defined carbon nanorings. Nature Chem. 5, 572-576 (2013).

19. Otero, G. et al. Fullerenes from aromatic precursors by surface-catalysed cyclodehydrogenation. Nature 454, 865-868 (2008).

20. Amsharov, K. et al. Towards the isomer-specific synthesis of higher fullerenes and buckybowls by the surface-catalyzed cyclodehydrogenation of aromatic precursors. Angew. Chem. Int. Edn Engl. 49, 9392-9396 (2010).

21. Rim, K. T. et al. Forming aromatic hemispheres on transition-metal surfaces. Angew. Chem. Int. Edn Engl. 46, 7891-7895 (2007).

22. Gavillet, J. et al. Root-growth mechanism for single-wall carbon nanotubes. Phys. Rev. Lett. 87, 275504 (2001).

23. Dresselhaus, M. S., Dresselhaus, G., Saito, R. \& Jorio, A. Raman spectroscopy of carbon nanotubes. Phys. Rep. 409, 47-99 (2005). 
24. Jorio, A. et al. Quantifying carbon-nanotube species with resonance Raman scattering. Phys. Rev. B 72, 075207 (2005).

25. Soares, J. S. \& Jorio, A. Study of carbon nanotube-substrate interaction. J. Nanotechnol. 2012, 1-10 (2012).

26. Jorio, A. et al. Linewidth of the Raman features of individual single-wall carbon nanotubes. Phys. Rev. B 66, 115411 (2002).

27. Telg, H. et al. Chiral index dependence of the $\mathrm{G}^{+}$and $\mathrm{G}^{-}$Raman modes in semiconducting carbon nanotubes. ACS Nano 6, 904-911 (2012).

28. Piscanec, S., Lazzeri, M., Robertson, J., Ferrari, A. \& Mauri, F. Optical phonons in carbon nanotubes: Kohn anomalies, Peierls distortions, and dynamic effects. Phys. Rev. B 75, 035427 (2007).

29. Rao, A. M. et al. Diameter-selective Raman scattering from vibrational modes in carbon nanotubes. Science 275, 187-191 (1997).

30. $\mathrm{Xu}, \mathrm{Y} . \mathrm{Q}$. et al. Vertical array growth of small diameter single-walled carbon nanotubes. $J$. Am. Chem. Soc. 128, 6560-6561 (2006).

Acknowledgements This research was supported in part by the Swiss National Science Foundation and by the State Secretariat for Education, Research and Innovation via the COST Action MP0901 'NanoTP'. K.A. acknowledges financial support from Deutsche Forschungsgemeinschaft.

Author Contributions K.A., M.J. and R.F. initiated and conceived this work. K.A. designed the precursor molecules and the corresponding synthetic routes, K.A. and A.M. synthesised precursor molecules and performed HPLC, NMR and MS analyses. J.R.S.-V. carried out on-surface synthesis work. J.R.S.-V. and T.D. performed STM and Raman measurements, I.S. did the He ion microscopy analysis. O.G. performed the calculations. All authors participated in analysis and interpretation of the results. J.R.S.-V. drafted the manuscript, with contributions from P.R. and O.G. R.F. and K.A. edited the manuscript and coordinated the efforts of the research teams.

Author Information Reprints and permissions information is available at www.nature.com/reprints. The authors declare no competing financial interests. Readers are welcome to comment on the online version of the paper. Correspondence and requests for materials should be addressed to R.F. (roman.fasel@empa.ch) or K.A. (konstantin.amsharov@fau.de).

Figure 1 | Two-step bottom-up synthesis of SWCNTs. (1) Formation of singly capped ultrashort $(6,6)$ SWCNT seed S1 via cyclodehydrogenation $(\mathrm{CDH})$ of the suitably designed polyaromatic hydrocarbon precursor $\mathrm{C}_{96} \mathrm{H}_{54}$ (P1). (2) Nanotube growth via epitaxial elongation (EE). Parts of the 
precursor P1 involved in the formation of the SWCNT end cap and the ultrashort CNT segment of the seed S1 are highlighted in yellow and blue, respectively. Red dashed lines indicate the new C-C bonds formed upon CDH. Epitaxial elongation occurs via the successive addition of carbon species, as indicated in green.

Figure 2 | Formation of $(6,6)$ SWCNT seeds S1. a, b, Illustration of the thermally induced surface catalysed CDH to form the $(6,6)$ SWCNT seed S1 from the adsorbed precursor P1. c, d, STM images of precursor molecules as deposited on $\operatorname{Pt}(111)$ (c) and after annealing to $770 \mathrm{~K}$ (d). e, Close-up STM image of a precursor (top) and the corresponding simulation based on the extended LUMO (greyscale) with a structural model of the molecule superimposed (bottom). f, Line profiles (positions indicated in $\mathbf{c}, \mathbf{d}$ ) over an as-deposited precursor P1 (grey line) and the seed species S1 obtained after annealing to $770 \mathrm{~K}$ (black line). g, Close-up STM images taken at $-1 \mathrm{~V}$ and $0.1 \mathrm{~V}$ of $(6,6)$ SWCNT seed S1 (left) and the corresponding simulations of HOMO and LUMO, respectively (greyscale, right).

\section{Figure 3 | Epitaxial elongation of singly capped SWCNT with $(6,6)$ chiral index defined by the} seed S1. a-c, Schematic illustration of the epitaxial elongation of $(6,6)$ SWCNT seeds S1 via surface-catalysed $\mathrm{C}_{2}$ incorporation at the nanotube/metal interface. The use of ethanol as a carbon feedstock gas is illustrated, which decomposes on the hot, reactive Pt surface into $\mathrm{C}_{2}$ species and binds 'epitaxially' to the bay region of the previously formed singly capped SWCNT, resulting in an elongation of the tube along its axis. d-f, STM images of the as-prepared $(6,6)$ SWCNT seeds (d), and after exposure to low doses of ethylene of $1 \mathrm{~L}$ (e) and $5 \mathrm{~L}$ (f), respectively, at a temperature of $770 \mathrm{~K}$. For direct comparison, the same height colour scale is used for $\mathbf{d}-\mathbf{f}$. g, Line profiles taken across the features indicated by arrow pairs in the corresponding STM images $\mathbf{d}-\mathbf{f}$. h, i, STM images of a sample exposed to a pressure of $1 \times 10^{-7}$ mbar of ethanol for $1 \mathrm{~h}(270 \mathrm{~L})$ at a temperature of $770 \mathrm{~K}$. A long SWCNT is observed to lie on the rough surface (h). A close-up STM image (i) identifies it as a $(6,6)$ SWCNT.

\section{Figure 4 | SWCNT orientation determination and single chirality assessment by Raman}

spectroscopy. a, Raman spectra of epitaxially elongated $(6,6)$ SWCNTs obtained by exposing seeds S1 to a pressure of $1 \times 10^{-7} \mathrm{mbar}$ of ethanol for $30 \mathrm{~min}(140 \mathrm{~L})$ at a temperature of $670 \mathrm{~K}$. The spectra were acquired with the sample surface perpendicular (grey curve) and at an angle of $30^{\circ}$ (black curve) to the laser beam. b, Raman spectrum of longer SWCNTs ( $1 \mathrm{~h}$ at $1 \times 10^{-7}$ mbar of ethanol at $670 \mathrm{~K} ; 270 \mathrm{~L})$ for a short laser illumination time $(30 \mathrm{~s})$, revealing defect-free SWCNTs as judged by the absence of a $\mathrm{D}$ peak. The insets show further details on the very narrow RBM at 
$295 \mathrm{~cm}^{-1}$ as measured with a beam diameter of 1.5 (filled circles) and $10 \mu \mathrm{m}$ (open circles), respectively, and the splitting of the $\mathrm{G}$ band into a $\mathrm{G}^{+}$component at 1,591 and a $\mathrm{G}^{-}$component at $1,518 \mathrm{~cm}^{-1}$, which is characteristic of $(6,6)$ SWCNTs.

\section{METHODS}

\section{Substrates and surface preparation}

$\operatorname{Pt}(111)$ single crystals (Surface Preparation Laboratory, Netherlands) were used as substrates for $(6,6)$ SWCNT synthesis. The base pressure of the ultrahigh vacuum system was at $5 \times 10^{-11} \mathrm{mbar}$. Surface cleaning was performed by standard cycles of sputtering with $1 \mathrm{keV} \mathrm{Ar}^{+}$ions, first at room temperature and then at $1,100 \mathrm{~K}$, followed by a last flash annealing to $1,370 \mathrm{~K}$ without ion bombardment.

\section{Preparation of $(6,6)$ SWCNT seeds S1}

Precursor molecules $\mathrm{C}_{96} \mathrm{H}_{54}$ were deposited in ultrahigh vacuum from a Knudsen-cell type evaporator onto a previously cleaned $\operatorname{Pt}(111)$ surface held at room temperature. The strong interaction between metal surfaces from the platinum group and polycyclic aromatic hydrocarbons largely suppresses the mobility of the adsorbed molecules, as revealed by the avoided step decoration or island formation. Thus interactions with surrounding molecules and step edges are largely suppressed, allowing for the unperturbed $\mathrm{CDH}$ of the precursor in the following step. A postannealing at $470 \mathrm{~K}$ reduced significantly the surface contaminants without triggering the intramolecular dehydrogenation of the molecules. Further annealing at $770 \mathrm{~K}$ induces the complete CDH of the molecules forming the desired $(6,6)$ SWCNT seeds $\mathbf{S 1}$.

\section{Epitaxial elongation}

The carbon source used for elongation was ethylene or ethanol (no significant differences between the use of ethylene or ethanol as carbon feedstock were noticed) that was dosed through a ultrahigh vacuum leak valve at a pressure of $1 \times 10^{-7}$ mbar while the substrates were heated to temperatures between 400 and $500{ }^{\circ} \mathrm{C}$ for a duration of 30 and $60 \mathrm{~min}$, achieving doses of 140 and $270 \mathrm{~L}$, respectively (1 Langmuir $(\mathrm{L})$ is the dose resulting from exposure to a partial pressure of $1.3 \times 10^{-6}$ mbar for one second). For better control on low exposures, a pressure of $1 \times 10^{-8} \mathrm{mbar}$ was used to achieve doses of 1 and $5 \mathrm{~L}$. Longer growth times or higher pressures were not explored to avoid too long recovery times of the $<10^{-10}$ mbar base pressure of the ultrahigh vacuum system used. 


\section{Simulations}

The HOMO/LUMO simulations were carried out on AMBER force field relaxed structures of the precursor monomer P1 and the $(6,6)$ SWCNT seed S1. Charge density contours of the frontier orbitals were computed by extended Hückel theory with the HyperChem 7.5 software.

\section{Characterization methods}

STM measurements were performed in constant current mode using an Omicron LT-STM with liquid nitrogen cooling $(77 \mathrm{~K})$. The scanning parameters for the STM images shown in the manuscript were: Fig. 2: $0.05 \mathrm{~V}, 50$ pA (c, e); $0.1 \mathrm{~V}, 100$ pA (d); $-1 \mathrm{~V} / 0.1 \mathrm{~V}$ (indicated), $50 \mathrm{pA}$ (g). Figure 3: $0.1 \mathrm{~V}, 100 \mathrm{pA}(\mathbf{d}) ; 0.1 \mathrm{~V}, 50 \mathrm{pA}(\mathbf{e}) ; 0.5 \mathrm{~V}, 30 \mathrm{pA}(\mathbf{f}), 1 \mathrm{~V}, 50 \mathrm{pA}(\mathbf{h}) ; 0.1 \mathrm{~V}, 50 \mathrm{pA}(\mathbf{i})$. Micro-Raman spectra were recorded in backscattering configuration in a Bruker Senterra instrument with a spectral resolution of $3-5 \mathrm{~cm}^{-1}$ using a $532 \mathrm{~nm}$ laser of $20 \mathrm{~mW}$ power focused on the sample through a $50 \times$ or $10 \times$ magnifying objective (beam diameter $1.5 \mu \mathrm{m}$ and $10 \mu \mathrm{m}$, respectively). Although the $2.33 \mathrm{eV}$ energy of the $532 \mathrm{~nm}$ laser is not in resonance with the first optical transition of the $(6,6)$ SWCNT of $2.69 \mathrm{eV}$ (ref. 24), reasonably high Raman intensity was observed. SHIM measurements were performed in a Carl Zeiss Orion Plus instrument with a beam energy of $30 \mathrm{keV}$ and a beam current of $0.4 \mathrm{pA}$.

Mass spectra were recorded on a Shimadzu AXIMA Resonance spectrometer. NMR spectra were measured at $20^{\circ} \mathrm{C} . R_{\mathrm{f}}$ values were determined either on silica gel coated TLC-PET sheets with fluorescent indicator $254 \mathrm{~nm}$ excitation wavelength (silica gel layer thickness $0.25 \mathrm{~mm}$, medium pore diameter $60 \AA$ A, Fluka), or on neutral aluminium oxide coated TLC aluminium plates with fluorescent indicator for $254 \mathrm{~nm}$ excitation wavelength (DC Aluminiumoxid $60 F_{254}$, medium pore diameter $60 \AA$, Merck). Chromatographic purifications were carried out with flash grade silica gel Kieselgel $60(0.06-0.2 \mathrm{~mm})$. Unless otherwise stated, all reactions were performed under an argon atmosphere. The commercially available reagents were used as received without further purification.

\section{Precursor synthesis}

The SWCNT precursor P1 was obtained by multistep organic synthesis according to the synthetic route shown in Extended Data Fig. 4. Benzo[c]phenanthrene, 2-bromo-6-methyl (1) was obtained by standard Wittig reaction of 2-acetonaphthone with (4-bromobenzyl)triphenylphosphonium bromide and subsequent photocyclization. Suzuki coupling of 1 with 2-biphenylboronic acid gave 2. Benzylic bromination with $\mathrm{N}$-bromosuccinimide and following treatment with sodium cyanide in DMSO gave 4. The cyano-compound was then hydrolysed to the corresponding acetic acid and converted to 6 in two steps. First, reaction with thionylchloride gave the acid chloride, which was then used in a Friedel-Crafts acylation to achieve ring closure. The last synthetic step, the conversion to precursor 
P1, was carried out by aldol cyclotrimerization using either $\mathrm{TiCl}_{4}$ or Brønsted acid conditions. Both cases lead to the desired trimer in satisfying yield.

\section{Benzo[c]phenanthrene, 2-bromo-6-methyl (1).}

$15.4 \mathrm{~g}$ (47.8 mmol) of [2-(4-bromophenyl)propenyl]naphthalene (the mixture of cis/trans isomers was used for photocyclization without any additional separation since both isomers interconvert under UV irradiation) were dissolved in 11 of cyclohexane in a photochemical reactor. After addition of $13.4 \mathrm{~g}$ of iodine ( $52.6 \mathrm{mmol})$, argon was bubbled through the stirred solution for $15 \mathrm{~min}$. An excess of propylene oxide $(55.5 \mathrm{~g}, 67 \mathrm{ml}, 0.96 \mathrm{~mol})$ was then added and the solution was irradiated for $8 \mathrm{~h}$. To remove residual iodine, the resulting mixture was washed with aqueous $\mathrm{Na}_{2} \mathrm{~S}_{2} \mathrm{O}_{3}$ solution, subsequently with $\mathrm{H}_{2} \mathrm{O}$, dried and concentrated. After washing with $\mathrm{H}_{2} \mathrm{O}$, drying over $\mathrm{Na}_{2} \mathrm{SO}_{4}$, filtration and concentration, a yellow orange oil was obtained. Recrystallization from petroleum ether gave $11.1 \mathrm{~g}$ ( $34.4 \mathrm{mmol}, 72 \%$ yield) of the product as a beige powder.

TLC (hexane, $\left.\mathrm{Al}_{2} \mathrm{O}_{3}\right): R_{\mathrm{f}}=0.47 ;{ }^{1} \mathrm{H}-\mathrm{NMR}\left(300 \mathrm{MHz}, \mathrm{CD}_{2} \mathrm{Cl}_{2}\right): \delta 9.08$ p.p.m. $(\mathrm{s}, 1 \mathrm{H}), 8.91(\mathrm{~d}$, $J=8.3 \mathrm{~Hz}, 1 \mathrm{H}), 8.00-7.85(\mathrm{~m}, 3 \mathrm{H}), 7.73(\mathrm{~d}, J=8.5 \mathrm{~Hz}, 1 \mathrm{H}), 7.67-7.53(\mathrm{~m}, 4 \mathrm{H}), 2.71(\mathrm{~d}, J=1.0 \mathrm{~Hz}$, $3 \mathrm{H}) ;{ }^{13} \mathrm{C}-\mathrm{NMR}\left(75 \mathrm{MHz}, \mathrm{CD}_{2} \mathrm{Cl}_{2}\right): \delta 133.44,133.34,131.99,131.42,130.78,130.35,130.26$, $129.51,129.22,128.62,128.12,127.92,127.17,126.79,126.75,126.36,122.66,119.59,20.36$; $\operatorname{HRMS}(\mathrm{m} / \mathrm{z}):[\mathrm{M}]^{+}$calculated for $\mathrm{C}_{19} \mathrm{H}_{13} \mathrm{Br}, 320.0201$; found 320.0202 .

\section{Benzo[c]phenanthrene,6-methyl-2-[1,1'-biphenyl]-2-yl (2).}

$3.13 \mathrm{~g}$ (15.8 mmol) of biphenyl-2-boronic acid, $3.9 \mathrm{~g}$ (12.1 mmol) of 2-bromo-6methylbenzophenanthrene, $690 \mathrm{mg}(0.6 \mathrm{mmol})$ of $\mathrm{Pd}\left(\mathrm{PPh}_{3}\right)_{4}$ and $7.9 \mathrm{~g}(24.2 \mathrm{mmol})$ of $\mathrm{Cs}_{2} \mathrm{CO}_{3}$ were dissolved in $400 \mathrm{ml}$ toluene and $200 \mathrm{ml} \mathrm{MeOH}$ before the mixture (yellow colour) was degassed. Then the mixture was heated to $110{ }^{\circ} \mathrm{C}$ under an argon atmosphere in an oil bath and stirred overnight. Subsequently, extraction was carried out with toluene, the organic phase was washed with $\mathrm{H}_{2} \mathrm{O}(3 \times 20 \mathrm{ml})$, dried with $\mathrm{Na}_{2} \mathrm{SO}_{4}$, filtered and stripped of solvent. Recrystallization from cyclohexane/petroleum ether and chromatographic purification of the residual mixture using cyclohexane $/ \mathrm{CH}_{2} \mathrm{Cl}_{2}$ resulted in $3.75 \mathrm{~g}(9.5 \mathrm{mmol}, 79 \%$ yield $)$ of the pure product as a white powder. Replacing $\mathrm{Cs}_{2} \mathrm{CO}_{3}$ by $\mathrm{K}_{2} \mathrm{CO}_{3}$ resulted in a dramatic decrease of the product yield.

TLC (hexane: $\left.\mathrm{CH}_{2} \mathrm{Cl}_{2} 1: 2 \mathrm{v} / \mathrm{v}\right): R_{\mathrm{f}}=0.47 ;{ }^{1} \mathrm{H}-\mathrm{NMR}\left(300 \mathrm{MHz}, \mathrm{CD}_{2} \mathrm{Cl}_{2}\right): \delta 8.57$ p.p.m. (s, 1H), $7.91(\mathrm{~d}, J=8.8 \mathrm{~Hz}, 1 \mathrm{H}), 7.85(\mathrm{dd}, J=8.0,1.4 \mathrm{~Hz}, 1 \mathrm{H}), 7.80(\mathrm{~d}, J=8.3 \mathrm{~Hz}, 3 \mathrm{H}), 7.63(\mathrm{~s}, 1 \mathrm{H})$, 7.49-7.41 (m, 3H), 7.40-7.28 (m, 6H), 7.27-7.18 (m, 2H), 7.15-7.07 (m, 1H), 2.69 (d, J=0.9 Hz, $3 \mathrm{H}) ;{ }^{13} \mathrm{C}-\mathrm{NMR}\left(75 \mathrm{MHz}, \mathrm{CD}_{2} \mathrm{Cl}_{2}\right): \delta 141.86,141.22,140.93,138.97,132.98,132.45,131.97$, 131.42, 130.96, 130.83, 130.36 (2 C), 130.19, 129.59, 129.03, 128.27 (2 C), 128.07, 128.02, 127.94, 
$127.70,127.68,127.66,127.59,127.29,127.17,126.66,126.45,125.76,122.52,20.20$; HRMS $(\mathrm{m} / \mathrm{z}):[\mathrm{M}]^{+}$calculated for $\mathrm{C}_{31} \mathrm{H}_{22}$ 394.1722; found 394.1719; MS LDI-TOF $(\mathrm{m} / \mathrm{z}):[\mathrm{M}]^{+}$isotopic distribution found: 394.20 (100), 395.20 (29.1), 396.22 (5.2); isotopic distribution calculated: 394.17 (100), 395.18 (33.5), 396.18 (5.4).

\section{Benzo[c]phenanthrene, 6-(bromomethyl)-2-[1,1'-biphenyl]-2-yl (3).}

$2 \mathrm{~g}(5.1 \mathrm{mmol})$ of compound 2 were dissolved in $70 \mathrm{ml}$ of $\mathrm{CCl}_{4}$ and $0.54 \mathrm{~g}(6.1 \mathrm{mmol}) \mathrm{N}$ bromosuccinimide was added while stirring. Then catalytic amounts of dibenzoylperoxide were added and the solution was refluxed for $14 \mathrm{~h}$. The resulting solution was cooled, filtered through a plug of silica gel with $\mathrm{CCl}_{4}$ as eluent and concentrated. Purification by column chromatography using $\mathrm{CCl}_{4}$ as eluent resulted in $1.67 \mathrm{~g}(3.5 \mathrm{mmol}, 70 \%$ yield $)$ of the product as yellow powder.

TLC $\left(\mathrm{CCl}_{4}\right): R_{\mathrm{f}}=0.42 ;{ }^{1} \mathrm{H}-\mathrm{NMR}\left(300 \mathrm{MHz}, \mathrm{CD}_{2} \mathrm{Cl}_{2}\right): \delta 8.57$ p.p.m. $(\mathrm{s}, 1 \mathrm{H}), 8.03(\mathrm{~d}$, $J=8.9 \mathrm{~Hz}, 1 \mathrm{H}), 7.90-7.83(\mathrm{~m}, 4 \mathrm{H}), 7.74$ (d, $J=8.5 \mathrm{~Hz}, 1 \mathrm{H}), 7.53-7.44$ (m, 3H), 7.35 (ddd, $J=13.0$, 10.8, 5.0 Hz, 6H), 7.28-7.20 (m, 2H), 7.16-7.09 (m, 1H), 4.97 (s, 2H); ${ }^{13} \mathrm{C}-\mathrm{NMR}\left(75 \mathrm{MHz}, \mathrm{CD}_{2} \mathrm{Cl}_{2}\right)$ : $\delta 141.66,140.94,140.88,140.72,133.13,131.52,131.35,131.23,130.87,130.37,130.30,130.10$, $129.77,128.88,128.79,128.63,128.58,128.39,128.33,128.16,127.96,127.93,127.73$, 127.64, 126.76, 126.73, 126.23, 121.91, 33.02; $\operatorname{HRMS~(m/z):~}[\mathrm{M}]^{+}$calculated for $\mathrm{C}_{31} \mathrm{H}_{21} \mathrm{Br}$ 472.0827; found 472.0824 .

\section{Benzo[c]phenanthrene, 6-acetonitrile-2-[1,1'-biphenyl]-2-yl (4).}

$1 \mathrm{~g}(2.11 \mathrm{mmol})$ of compound 3 was dissolved in $25 \mathrm{ml}$ of DMSO and $135 \mathrm{mg}$ (2.75 mmol, 30\% excess) $\mathrm{NaCN}$ dissolved in $5 \mathrm{ml}$ DMSO was added. The solution was stirred at room temperature overnight. Then the mixture was diluted with $300 \mathrm{ml} \mathrm{CH}_{2} \mathrm{Cl}_{2}$ and washed repeatedly with $\mathrm{H}_{2} \mathrm{O}$. The resulting aqueous phase was extracted once with fresh $\mathrm{CH}_{2} \mathrm{Cl}_{2}$ and the combined organic phase was dried over $\mathrm{Na}_{2} \mathrm{SO}_{4}$, filtered and concentrated. Flash chromatography using $\mathrm{CH}_{2} \mathrm{Cl}_{2} /$ petroleum ether (ratio 1:1) resulted in $353 \mathrm{mg}(0.84 \mathrm{mmol}, 40 \%$ yield) of the product as orange powder.

TLC (hexane: $\left.\mathrm{CH}_{2} \mathrm{Cl}_{2} 1: 1 \mathrm{v} / \mathrm{v}\right): R_{\mathrm{f}}=0.31 ;{ }^{1} \mathrm{H}-\mathrm{NMR}\left(300 \mathrm{MHz}, \mathrm{CD}_{2} \mathrm{Cl}_{2}\right): \delta 8.59$ p.p.m. (s, 1H), 7.95-7.85 (m, 4H), 7.80-7.71 (m, 2H), 7.58-7.45 (m, 3H), 7.44-7.28 (m, 6H), 7.28-7.20 (m, 2H), 7.17-7.09 (m, 1H), 4.15 (d, $J=0.8 \mathrm{~Hz}, 2 \mathrm{H}) ;{ }^{13} \mathrm{C}-\mathrm{NMR}\left(75 \mathrm{MHz}, \mathrm{CD}_{2} \mathrm{Cl}_{2}\right)$ : $\delta 141.67,140.96$, $140.84,140.52$, 133.04, 131.38, 131.23, 130.88, 130.37, 130.06, 129.80, 129.72, 128.55, 128.53, $128.47,128.40,128.33,128.27,128.22$, 128.02, 127.94, 127.65, 127.50, 127.01, 126.76, 126.36, 124.46, 120.60, 117.82, 22.58; HRMS (m/z): [M] calculated for $\mathrm{C}_{32} \mathrm{H}_{21} \mathrm{~N}$ 419.1674; found 419.1672; MS LDI-TOF (m/z): [M] ${ }^{+}$, isotopic distribution found: 419.20 (100), 420.20 (36.0), 421.20 (6.7); isotopic distribution calculated: 419.17 (100), 420.17 (34.6), 421.17 (5.8). 


\section{Benzo[c]phenanthrene, 6-acetic acid-2-[1,1'-biphenyl]-2-yl (5).}

Compound 4 (1.16 g, $2.77 \mathrm{mmol})$ was dissolved in acetic acid $(200 \mathrm{ml})$ in a $500 \mathrm{ml}$ round-bottom flask and concentrated sulphuric acid $(20 \mathrm{ml})$ and water $(20 \mathrm{ml})$ were added. The orange solution was heated under reflux for $16 \mathrm{~h}$. After cooling down, $\mathrm{H}_{2} \mathrm{O}(200 \mathrm{ml})$ was added and the resulting mixture was vacuum filtered, repeatedly washed with $\mathrm{H}_{2} \mathrm{O}$ and vacuum dried, resulting in the product as beige powder $(1.2 \mathrm{~g}, 98 \%$ yield $)$.

TLC $\left(\mathrm{CH}_{2} \mathrm{Cl}_{2}:\right.$ EtOAc 5:1 v/v): $R_{\mathrm{f}}=0.47 ;{ }^{1} \mathrm{H}-\mathrm{NMR}\left(300 \mathrm{MHz}, \mathrm{CD}_{2} \mathrm{Cl}_{2}\right): \delta 8.58$ p.p.m. $(\mathrm{s}, 1 \mathrm{H})$, 7.89-7.81 (m, 2H), 7.82-7.70 (m, 4H), 7.53-7.43 (m, 3H), 7.43-7.28 (m, 6H), 7.28-7.20 (m, 2H), 7.17-7.08 (m, 1H), $4.11(\mathrm{~s}, 2 \mathrm{H}) ;{ }^{13} \mathrm{C}-\mathrm{NMR}\left(75 \mathrm{MHz}, \mathrm{CD}_{2} \mathrm{Cl}_{2}\right): \delta 176.11,141.73,141.03,140.96$, $140.04,132.97,131.45,131.40,130.84,130.37,130.13,129.93,129.68,129.64,129.23,128.33$, $128.32,128.25,128.23,128.17,128.08,128.07,127.83,127.77,127.62,126.72,126.69,126.08$, 121.96, 39.20; HRMS (m/z): [M] $]^{+}$calculated for $\mathrm{C}_{32} \mathrm{H}_{22} \mathrm{O}_{2} 438.1620$; found 438.1625.

\section{Benz[a]acephenanthrylen-6(7H)-one, 11-[1,1'-biphenyl]-2-yl (6).}

Compound $5(0.5 \mathrm{~g}, 1.14 \mathrm{mmol})$ was stirred for $2 \mathrm{~h}$ at $65^{\circ} \mathrm{C}$ with more than 10 times excess of $\mathrm{SOCl}_{2}$. After cooling down to room temperature, $\mathrm{SOCl}_{2}$ was evaporated and a brown powder was obtained. The powder was dissolved in $\mathrm{CS}_{2}(40 \mathrm{ml})$ and $\mathrm{AlCl}_{3}(0.4 \mathrm{~g}, 3 \mathrm{mmol})$ was added in small portions while stirring under argon. A black solution resulted. After $3 \mathrm{~h}$ of stirring the solution was poured into ice, resulting in an orange mass. After extraction with $\mathrm{CH}_{2} \mathrm{Cl}_{2}$, the solution was dried with $\mathrm{Na}_{2} \mathrm{SO}_{4}$ and filtered. Purification by flash chromatography (eluent: $\mathrm{CH}_{2} \mathrm{Cl}_{2} / \mathrm{CCl}_{4}$ 1:1) gave a yellow powder $(0.28 \mathrm{~g}, 0.66 \mathrm{mmol}, 57 \%$ yield). When stored at room temperature in the open, partial decomposition was observed over the course of several months.

TLC (hexane: $\left.\mathrm{CH}_{2} \mathrm{Cl}_{2} 1: 3 \mathrm{v} / \mathrm{v}\right): R_{\mathrm{f}}=0.40 ;{ }^{1} \mathrm{H}-\mathrm{NMR}\left(300 \mathrm{MHz}, \mathrm{CD}_{2} \mathrm{Cl}_{2}\right): \delta 8.66$ p.p.m. $(\mathrm{s}$, $1 \mathrm{H}), 8.21(\mathrm{~s}, 1 \mathrm{H}), 8.08-8.01(\mathrm{~m}, 1 \mathrm{H}), 7.96-7.87(\mathrm{~m}, 2 \mathrm{H}), 7.72(\mathrm{~s}, 1 \mathrm{H}), 7.59(\mathrm{dd}, J=8.3,1.7 \mathrm{~Hz}, 1 \mathrm{H})$, 7.57-7.45 (m, 4H), 7.45-7.38 (m, 2H), 7.34-7.26 (m, 2H), 7.24-7.16 (m, 2H), 7.07 (t, J=7.3 Hz, $1 \mathrm{H}), 3.74(\mathrm{~d}, J=1.1 \mathrm{~Hz}, 2 \mathrm{H}) ;{ }^{13} \mathrm{C}-\mathrm{NMR}\left(75 \mathrm{MHz}, \mathrm{CD}_{2} \mathrm{Cl}_{2}\right): \delta 202.77,141.84,140.97,140.67$, 139.76, 139.25, 133.95, 133.60, 133.03, 132.63, 132.47, 132.16, 131.54, 131.11, 130.41, 129.57, 129.50, 128.86, 128.80, 128.28, 128.24, 127.94, 127.85, 126.80, 126.40, 124.56, 124.18, 122.74, 41.87; HRMS (m/z): [M] ${ }^{+}$calculated for $\mathrm{C}_{32} \mathrm{H}_{20} \mathrm{O}$ 420.1514; found 420.1512; MS LDI-TOF ( $\left.\mathrm{m} / \mathrm{z}\right)$ : $[\mathrm{M}]^{+}$isotopic distribution found: 420.21 (100), 421.20(29); isotopic distribution calculated: 420.15 (100), 421.15 (34.6), $422.16(5.8)$. 


\section{$\mathrm{C}_{96} \mathrm{H}_{54}(\mathrm{P} 1)$}

Method A. A mixture of compound 6 (20 mg, $0.05 \mathrm{mmol}), p$-toluene sulphonic acid monohydrate (38 $\mathrm{mg}, 0.2 \mathrm{mmol})$, propionic acid $(0.015 \mathrm{ml}, 0.2 \mathrm{mmol})$ and $o$-dichlorobenzene $(2.4 \mathrm{ml})$ was transferred in a glass ampoule of $1 \mathrm{~cm}$ diameter. The glass ampoule was evacuated and sealed by melting while the reaction mixture was frozen by liquid nitrogen to prevent the solvent evaporating. The mixture was heated at $180{ }^{\circ} \mathrm{C}$ for $16 \mathrm{~h}$. After cooling down, the mixture was poured into $20 \mathrm{ml}$ of methanol. Addition of aqueous $\mathrm{NaOH}$ solution resulted in a precipitate which was subsequently vacuum filtered and washed with methanol, $\mathrm{H}_{2} \mathrm{O}$, acetone, $\mathrm{CH}_{2} \mathrm{Cl}_{2}$ and petroleum ether, resulting in a yellow powder (13 mg, $0.01 \mathrm{mmol}, 65 \%$ yield).

Method B. A mixture of compound $6(20 \mathrm{mg}, 0.05 \mathrm{mmol}), 2.4 \mathrm{ml}$ of $o$-dichlorobenzene, and $0.033 \mathrm{ml}$ of $\mathrm{TiCl}_{4}(6 \mathrm{M}$ equiv., $0.3 \mathrm{mmol})$ was transferred in a glass ampoule and sealed. The ampoule was heated at $180{ }^{\circ} \mathrm{C}$ for $16 \mathrm{~h}$. After cooling down, the glass ampoule was opened and the mixture was poured into $50 \mathrm{ml}$ of acetone. The precipitate was filtered, washed with acetone, DCM, and petroleum ether resulting in a yellow-brown solid (16 mg, 80\% yield). The compound was additionally purified by sublimation. No detectable decomposition as monitored by MS was observed after sublimation at $550^{\circ} \mathrm{C}, P=10^{-4}$ mbar (see Extended Data Fig. 5).

$\operatorname{HRMS}(\mathrm{m} / \mathrm{z})$ : $[\mathrm{M}]^{+}$calculated for $\mathrm{C}_{96} \mathrm{H}_{54}$ 1,206.4304; found 1,206.4309; MS LDI-TOF $(\mathrm{m} / \mathrm{z})$ : $[\mathrm{M}]^{+}$, isotopic distribution found: 1,206.42 (95.8), 1,207.42 (100), 1,208.42 (54.4), 1,209.42 (20.2), 1,210.47 (0.4); isotopic distribution calculated: 1,206.43 (96.3), 1,207.43 (100), 1,208.43 (51.4), $1,209.43$ (17.4), 1,210.44 (4.4).

Extended Data Figure 1 | Conformations of precursor P1 adsorbed on Pt(111). a, Sketch of the molecular conformations due to the axial chirality of the benzo[c]phenanthrene fragments. $\mathbf{b}, \mathbf{c}$, Simulations of the extended HOMO (LUMO shows a similar structure) with the outer biphenyls at a lower (b) or higher (c) elevation (left), and with the corresponding molecular structure superposed (right). d-h, Conformational analysis of P1 (top) and STM images of observed conformations of the P1 molecules on $\operatorname{Pt}(111)$ (bottom). i, Statistical analysis of the different molecular conformations shows that at least $50 \%$ of the molecules adopt a configuration suitable for a correct dehydrogenation pathway (red square).

\section{Extended Data Figure 2 | Dehydrogenation pathways for 'right' and 'wrong' conformations of}

P1. a-d, Molecular dehydrogenation pathways for a 'right' conformation (a), and for 'wrong' conformations with 1 (b), 2 (c) and 3 (d) biphenyl arms rotated. Cases $\mathbf{b}$, c, and $\mathbf{d}$ do not lead to a 
completed singly capped SWCNT and do not act as seeds for nanotube growth on epitaxial elongation.

Extended Data Figure 3 | Scanning helium ion microscopy images. SHIM images of epitaxially elongated SWCNTs obtained by exposing seeds S1 to $1 \times 10^{-7}$ mbar of ethanol for $1 \mathrm{~h}(270 \mathrm{~L})$ at $770 \mathrm{~K}$. Long carbon nanotubes can be observed to lie on the surface, and in some cases to shake under the ion beam (indicated by light green arrows, down). Top left, lower-magnification view of surface: numbered coloured boxes are shown at higher magnification to the right. The unnumbered grey scale images show different surface locations at higher magnifications. The rightmost panel gives a higher magnification image of the long SWCNT seen in panel 1.

Extended Data Figure 4 | Synthesis of SWCNT precursor P1. Details are given in Methods: here we describe reaction steps a to j. a, $\mathrm{PPh}_{3}$, toluene, reflux, $95 \%$; $\mathbf{b}, \mathrm{BrPh}_{3} \mathrm{PCH}_{2} \mathrm{PhBr}, \mathrm{KOtBu}, \mathrm{EtOH}$, reflux, $81 \%$; c, $\mathrm{I}_{2}$, $h v$, propylene oxide, cyclohexane, $72 \%$; d, $\mathrm{Pd}\left(\mathrm{PPh}_{3}\right)_{4}, \mathrm{Cs}_{2} \mathrm{CO}_{3}$, toluene/MeOH, $110^{\circ} \mathrm{C}, 79 \%$; e, NBS, DBPO, $\mathrm{CCl}_{4}$, reflux, $70 \%$; f, $\mathrm{NaCN}, \mathrm{DMSO}, \mathrm{RT}, 40 \%$; g, $\mathrm{H}_{2} \mathrm{SO}_{4}, \mathrm{H}_{2} \mathrm{O}, \mathrm{HOAc}$, reflux, $98 \%$; h, $\mathrm{SOCl}_{2}, 65{ }^{\circ} \mathrm{C} ; \mathbf{i}, \mathrm{AlCl}_{3}, \mathrm{CH}_{2} \mathrm{Cl}_{2}, \mathrm{RT}, 57 \%$; j, propanoic acid, TsOH, o-DCB, $180{ }^{\circ} \mathrm{C}$, $65 \%$.

Extended Data Figure 5 | LDI mass spectra of precursor P1 $\left(\mathbf{C}_{96} \mathbf{H}_{54}\right)$. a, b, LDI mass spectra of P1 before (a) and after (b) sublimation. Computed and experimentally observed isotope distribution patterns for $\mathrm{C}_{96} \mathrm{H}_{54}$ are given in the inset of $\mathbf{b}$. 


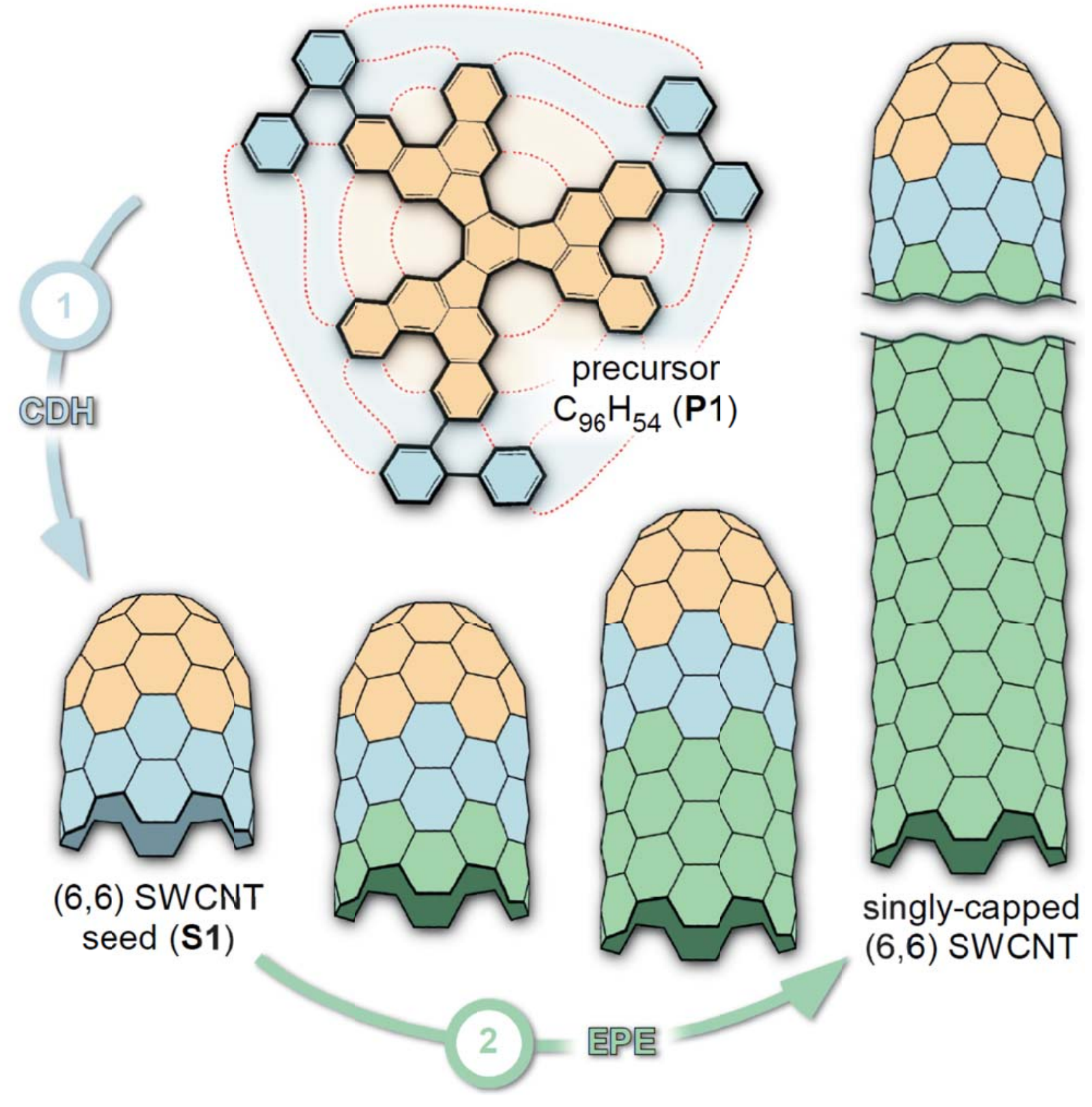

Figure 1 

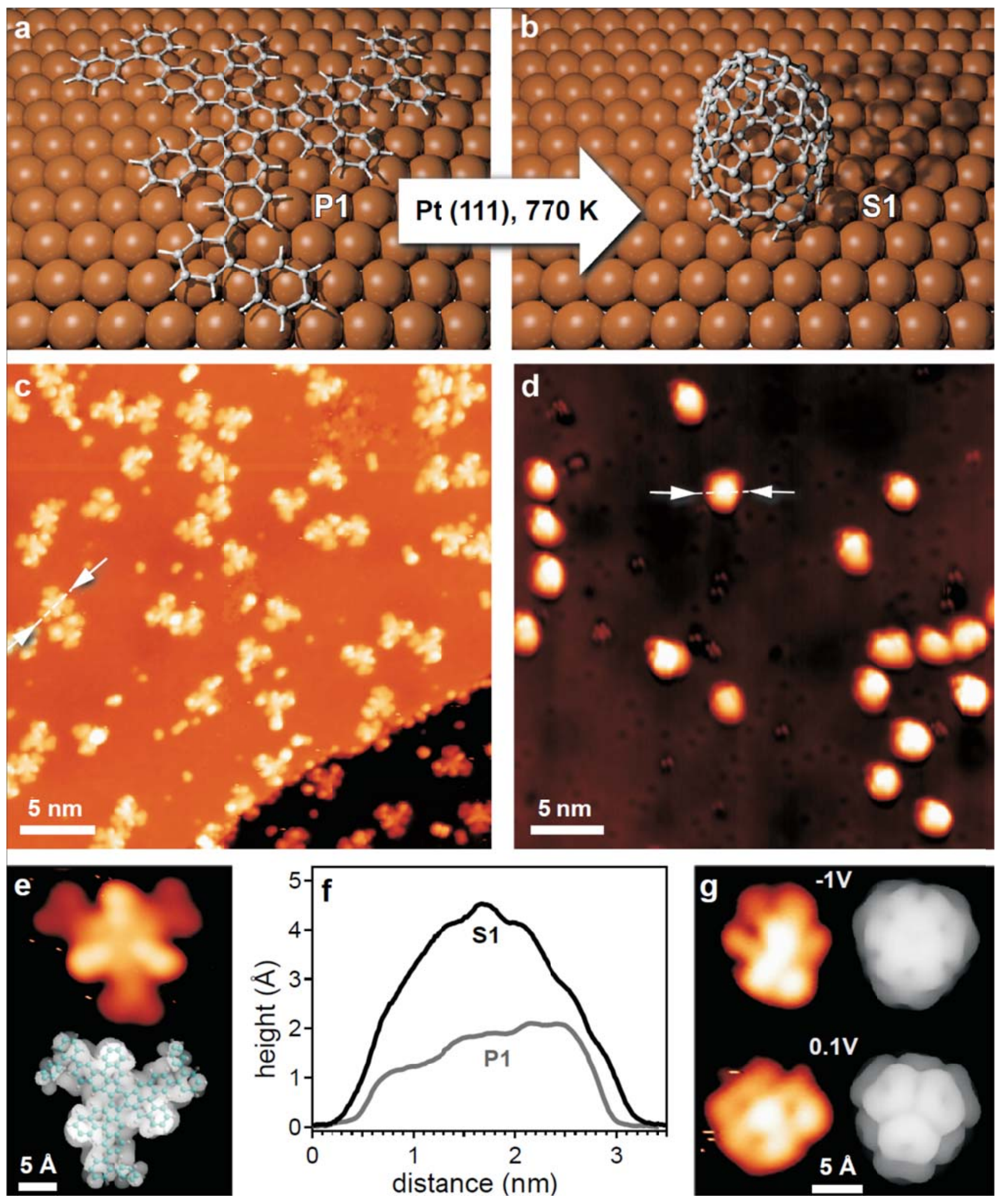

Figure 2 

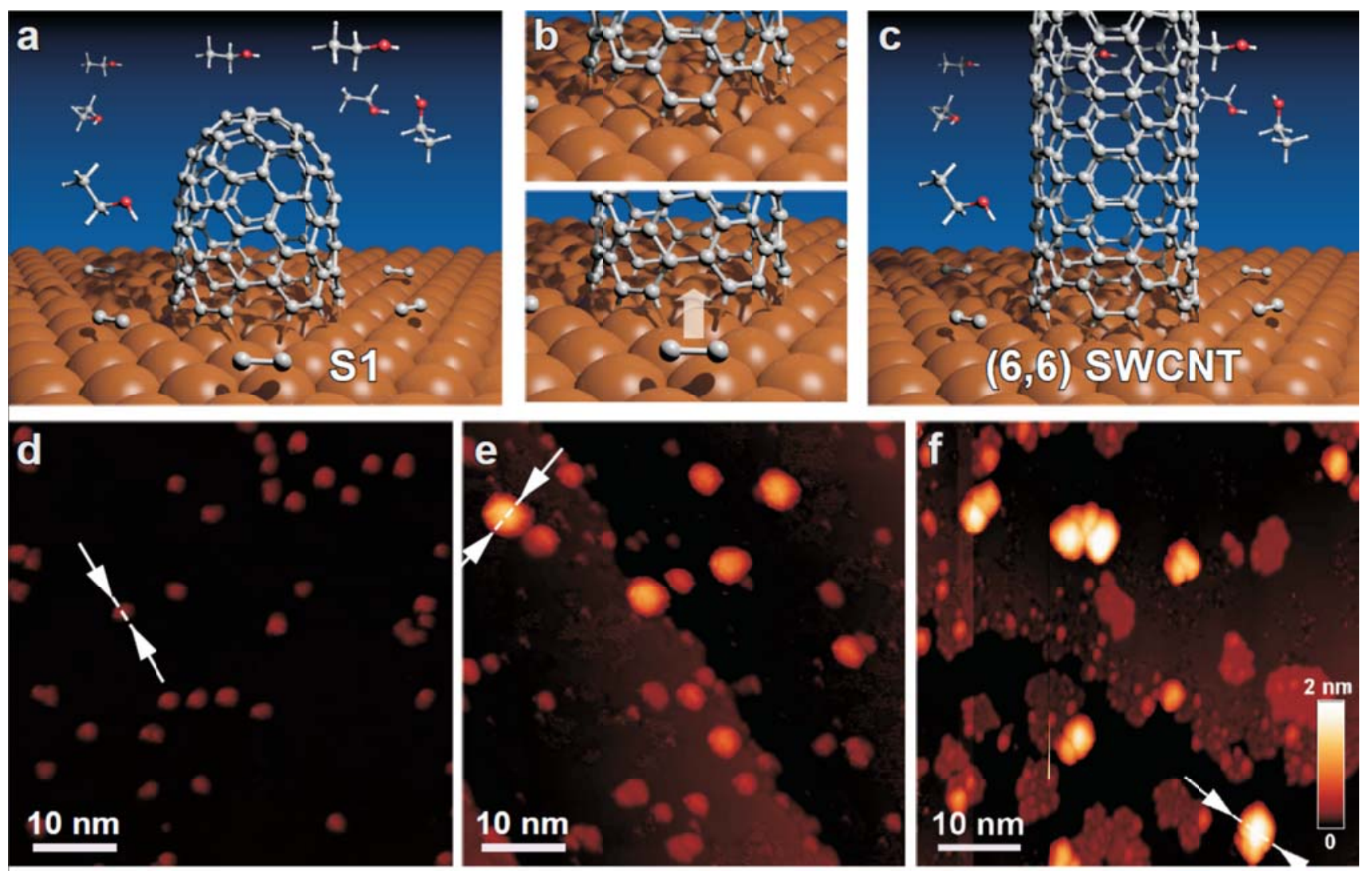

g
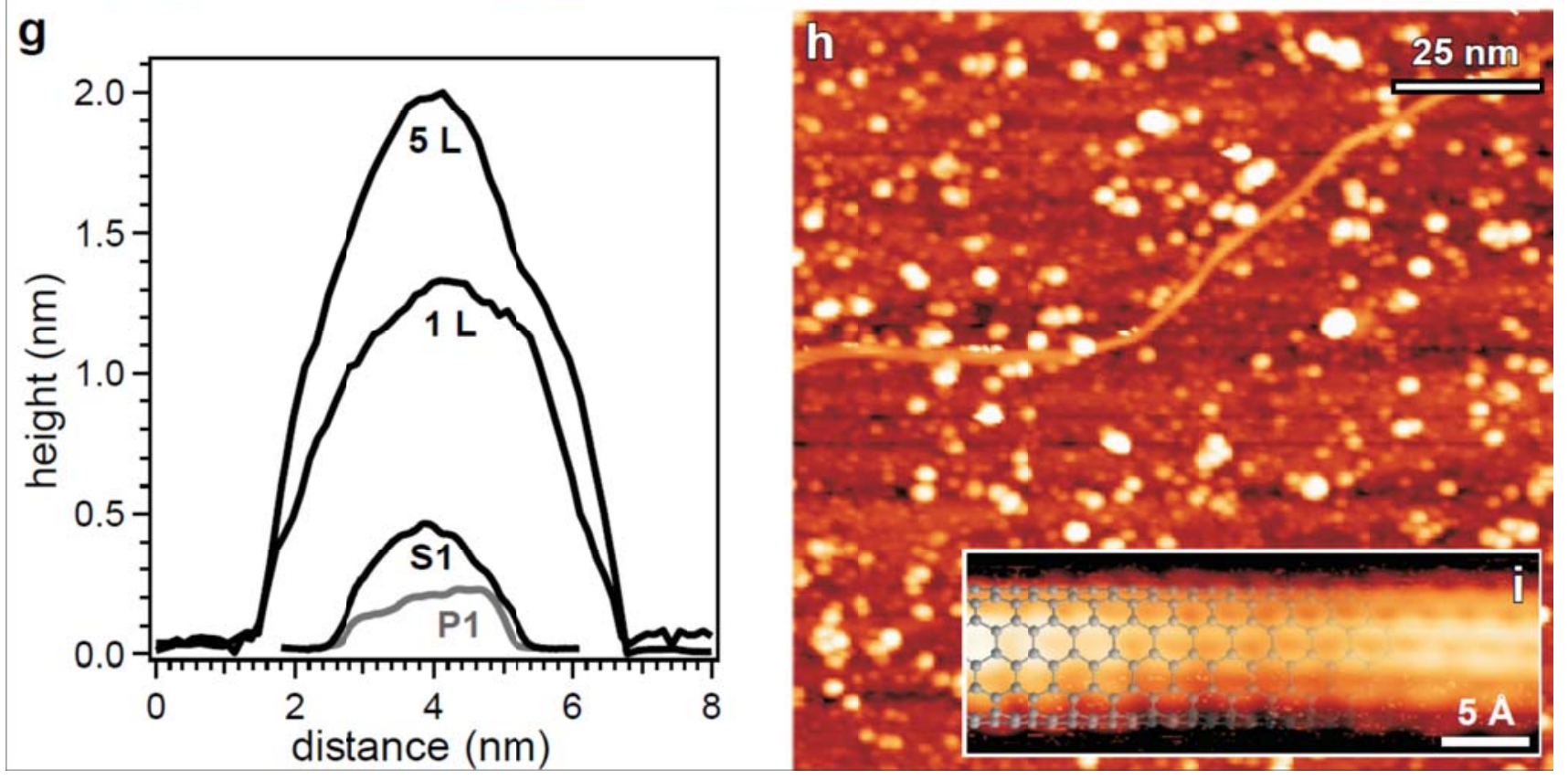

Figure 3 

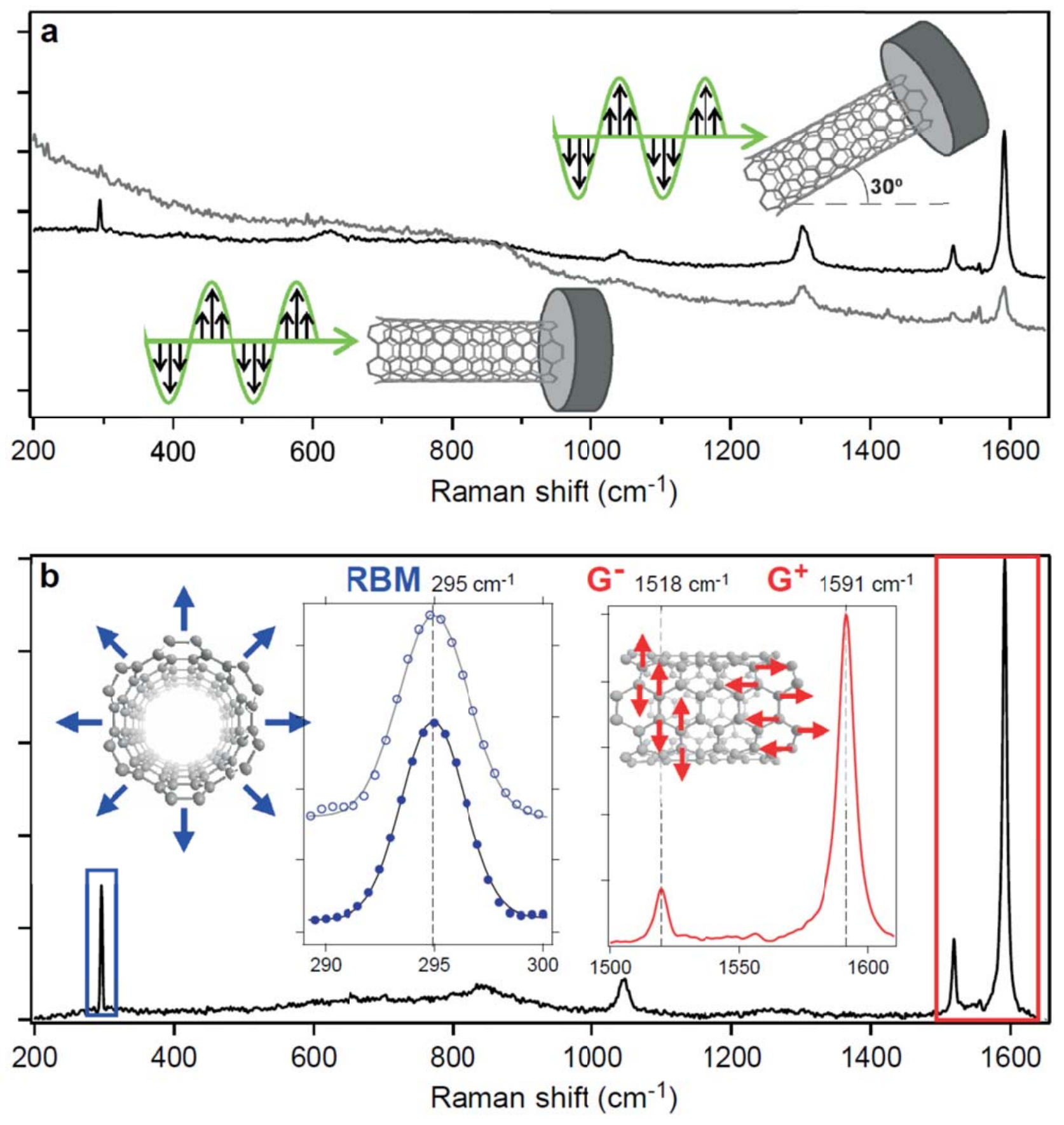

Figure 4 

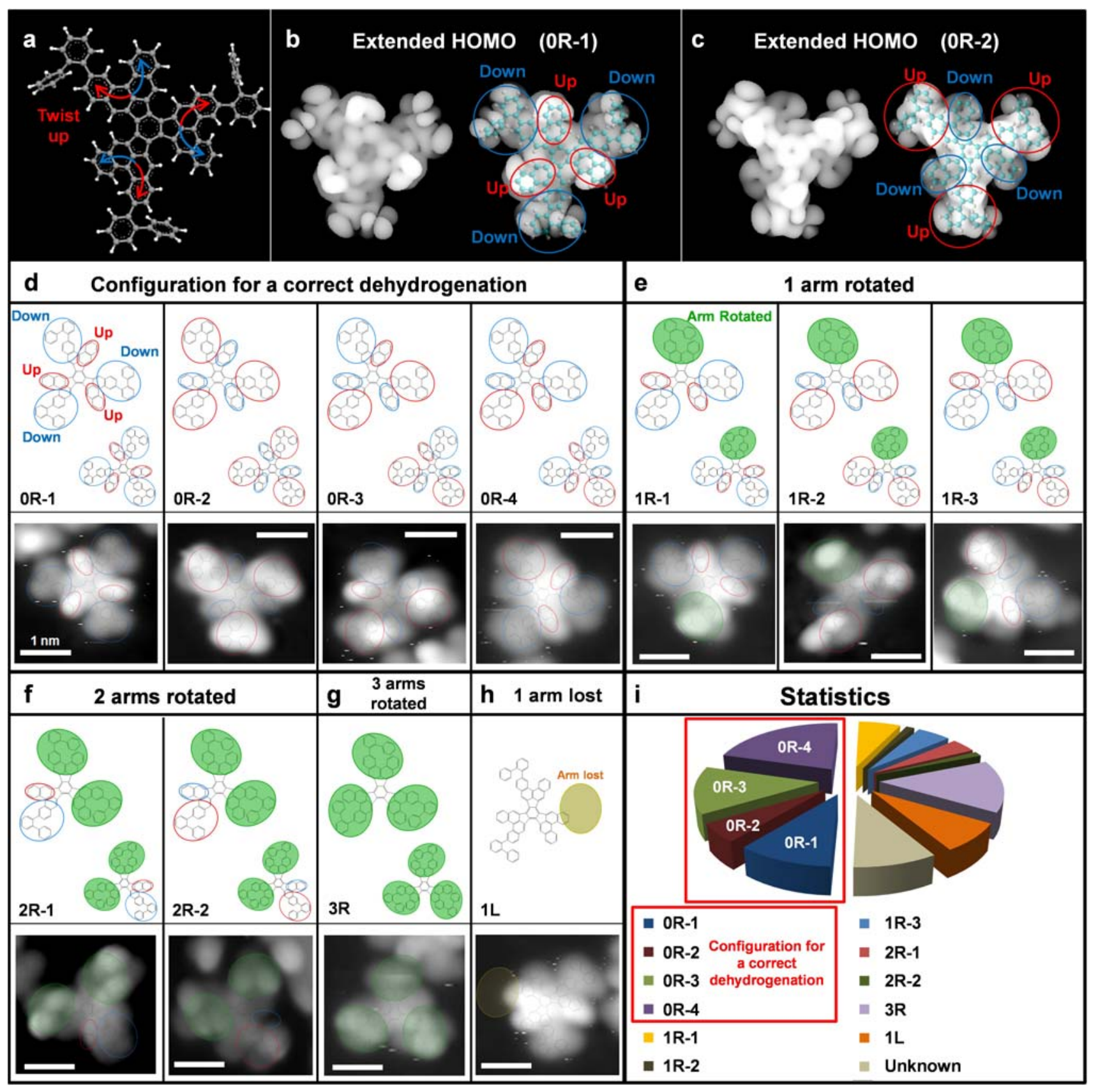

Extended Data Figure 1 


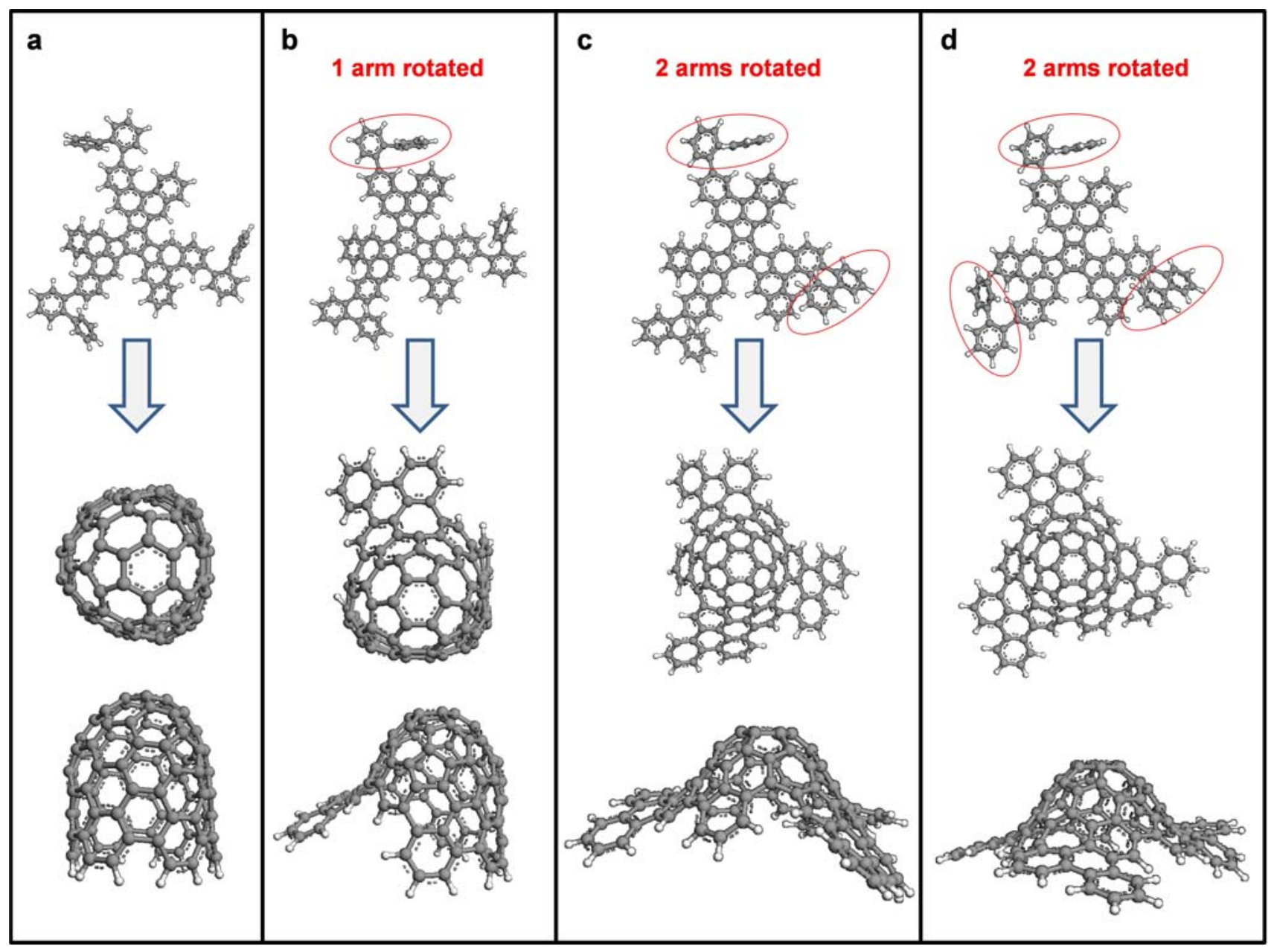

Extended Data Figure 2 
Publisher: NPG; Journal: Nature: Nature; Article Type: Physics letter DOI: 10.1038 /nature13607

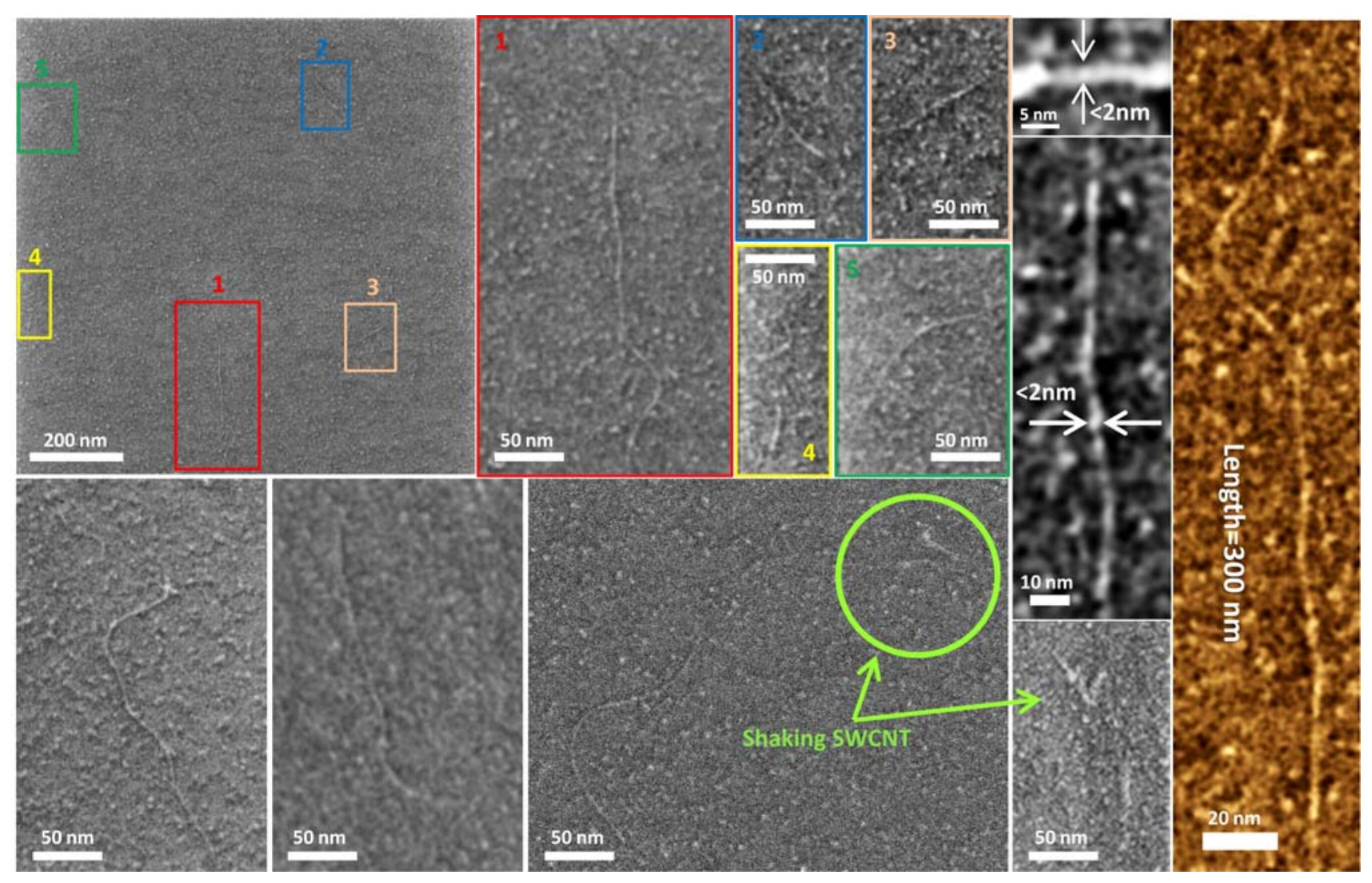

Extended Data Figure 3 
<smiles>CC(=O)c1ccc2ccccc2c1</smiles><smiles>Cc1cc2ccc(-c3ccccc3-c3ccccc3)cc2c2c1ccc1ccccc12</smiles>

2

6

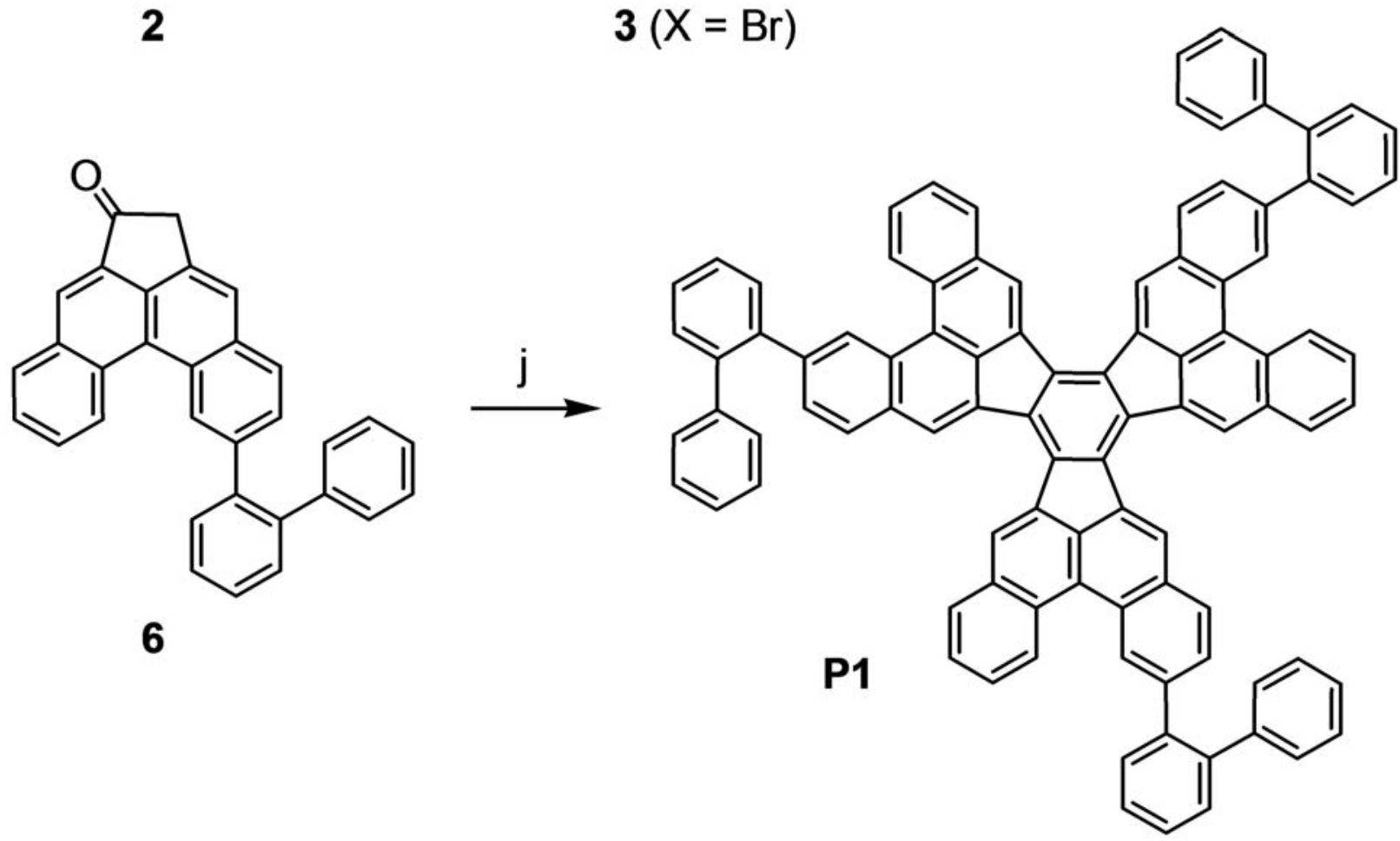<smiles>CC(=Cc1ccc(Br)cc1)c1ccc2ccccc2c1</smiles><smiles>[Y]Cc1cc2ccc(-c3ccccc3-c3ccccc3)cc2c2c1ccc1ccccc12</smiles>

$3(\mathrm{X}=\mathrm{Br})$<smiles>Cc1cc2ccc(Br)cc2c2c1ccc1ccccc12</smiles>

Extended Data Figure 4 

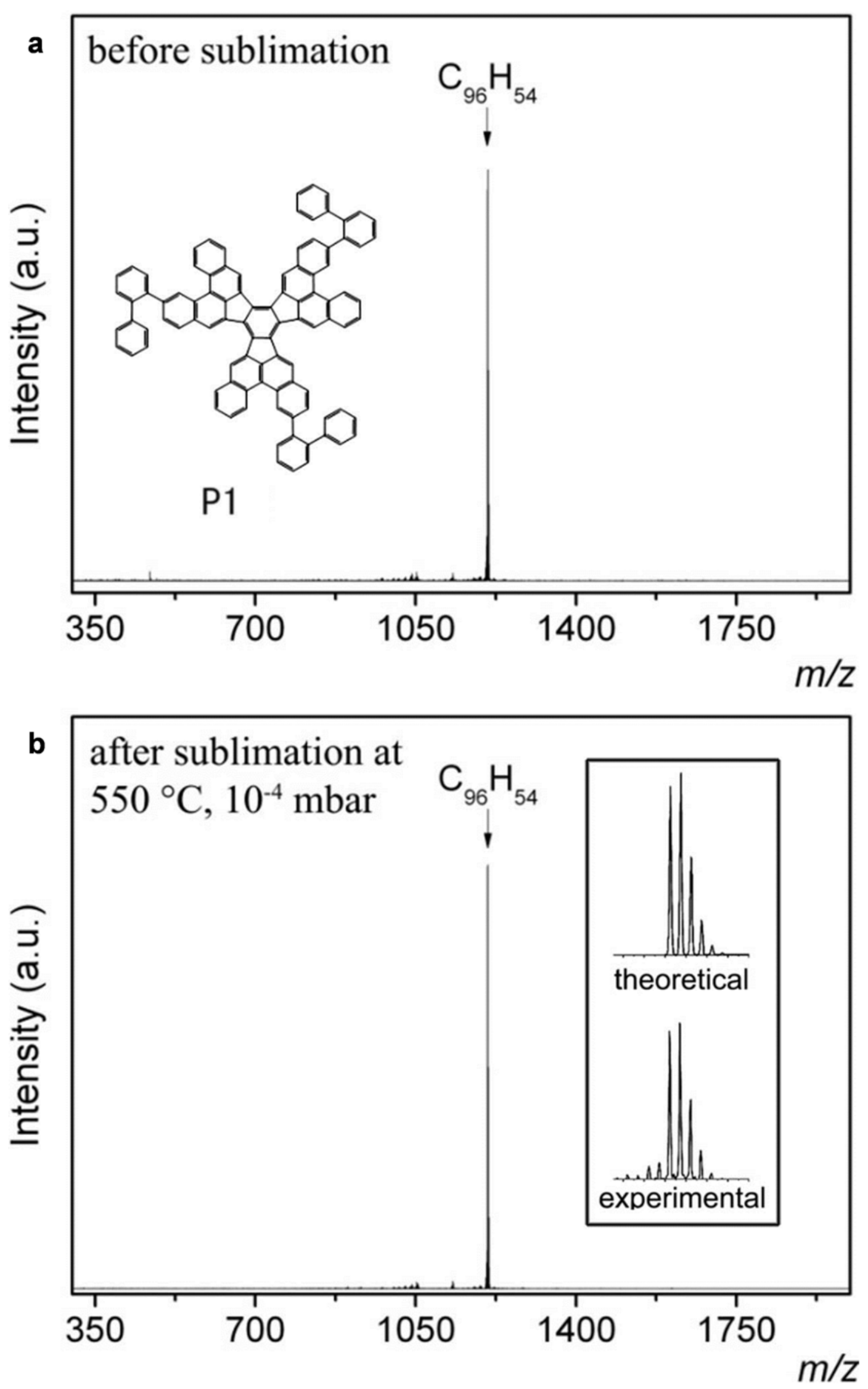

Extended Data Figure 5 